\title{
Population size of the jumbo squid Dosidicus gigas in the central Gulf of California, Mexico, based on mark-recapture data
}

\author{
Enrique Morales-Bojórquez ${ }^{1, *}$, Agustín Hernández-Herrera ${ }^{2}$, \\ Manuel O. Nevárez-Martínez ${ }^{3}$ Juan Gabriel Díaz-Uribe ${ }^{4}$ \\ ${ }^{1}$ Centro de Investigaciones Biológicas del Noroeste SC (CIBNOR), CP 23090, La Paz, Baja California Sur, México \\ ${ }^{2}$ Centro Interdisciplinario de Ciencias Marinas, IPN, CP 23000, La Paz, Baja California Sur, México \\ ${ }^{3}$ Instituto Nacional de Pesca, CRIP Guaymas, CP 85400, Guaymas, Sonora, México \\ ${ }^{4}$ Instituto Nacional de Pesca, CRIP La Paz, CP 23020, La Paz, Baja California Sur, México
}

\begin{abstract}
The use of mark-recapture data can be an alternative to other methods for estimating abundance of the jumbo squid Dosidicus gigas and can be used when catch-per-unit-effort data applied to depletion models or estimates from survey research are not available. Two markrecapture events were analyzed in the central Gulf of California, Mexico, during October 2001 and April 2002 to assess the status of jumbo squid. Results from October 2001 yielded a population size of 20.2 million squid with a $95 \%$ CI of 16 to 26.5 million squid $(p<0.05)$. In April the population size was estimated at 132.6 million squid with a $95 \%$ CI of 85.5 to 222 million squid ( $p<0.05$ ). The results for October and April show 2 different periods of abundance. Estimates of tag return rates were higher in April (5.5\%) than in October (1.7\%), and recruitment is the most plausible explanation. In the Gulf of California, recruitment of jumbo squid commonly occurs during April and May.
\end{abstract}

KEY WORDS: Binomial distribution - Likelihood estimator - Mark-recapture - Population size · Dosidicus gigas

\section{INTRODUCTION}

The jumbo squid Dosidicus gigas provides an important fishery in the Gulf of California, Mexico. This fishery is an alternative when yields in the shrimp fishery fall. The landing records of the squid fishery have shown the largest catches to be during 1996 and 1997, followed by falling abundance in 1998 and 1999, and a new period of stability in landings observed since 2000 (Boyle \& Rodhouse 2005). For the jumbo squid fishery, the proportional escapement, set at $40 \%$, has been used as a management strategy since 1996 (Hernández-Herrera et al. 1998, Morales-Bojórquez et al. 2001a,b). According to Nevárez-Martínez et al. (2010) this value is an acceptable management strategy to avoid overfish- ing jumbo squid. In order to evaluate the effectiveness of this strategy, detailed knowledge of abundance is required (Beddington et al. 1990).

In this fishery, there are 3 fishing fleets in the Gulf of California, Mexico. Two fishing fleets are artisanal small boats, called pangas, equipped with outboard motors, and each has a crew of 2 fishers who use hand jigs. The 2 fishing fleets are distributed along both coasts (one on each coast) of the Gulf of California, in Guaymas, Sonora, and Santa Rosalía, Baja California Sur (Fig. 1). They do not cross the Gulf of California, and fishing activity occurs from April to October along the west coast off Santa Rosalía and from November to March along the east coast off Guaymas; fishing grounds are between ca. 1.5 and $6.5 \mathrm{~km}$ from the coasts. The third fishing fleet is a 


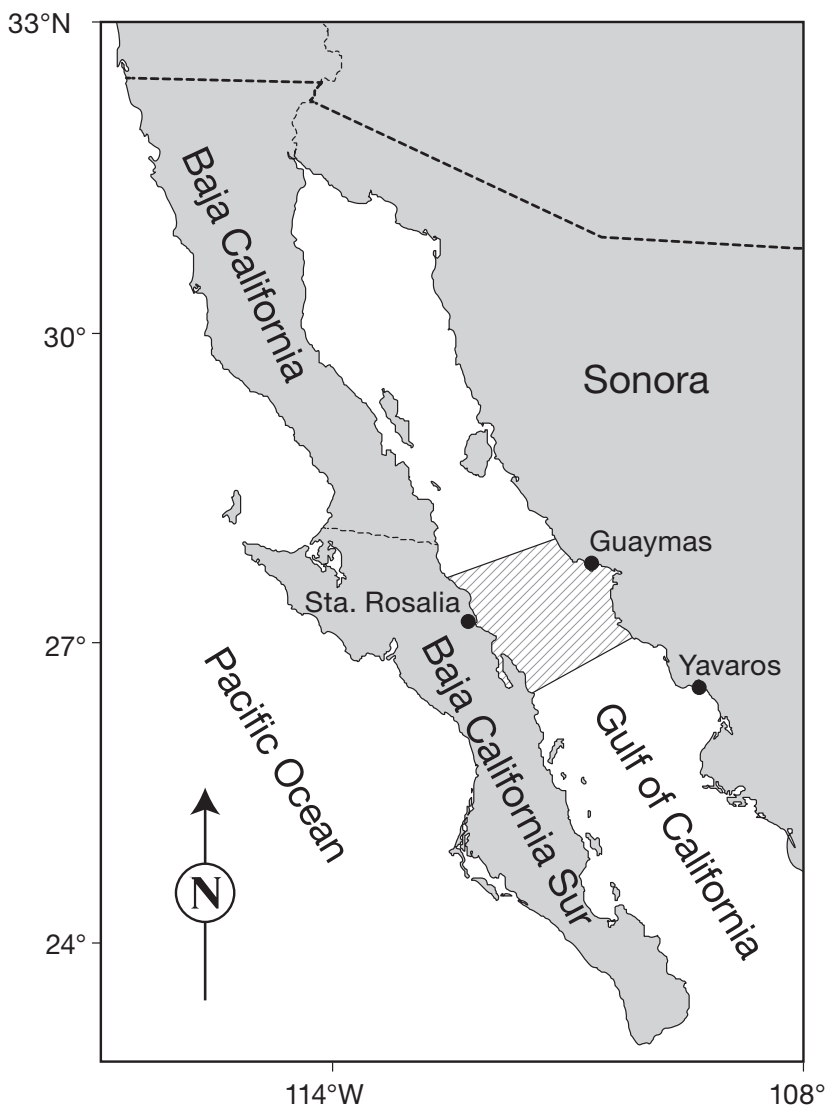

Fig. 1. Dosidicus gigas. Study area (hatched) in the central Gulf of California, Mexico. In this region, different biological events related to the population dynamics and demography of the jumbo squid have been identified, and the most important fishing grounds are in this area

shrimp trawler fleet adapted for squid fishing; each vessel with 6 to 10 fishers who use hand jigs. The fishing ground of this fleet is off Sonora (Fig. 1); although the fleet also crosses to Santa Rosalía for harvesting.

According to Ehrhardt et al. (1983), migration of jumbo squid into the Gulf of California begins in January and the squid reach their most northerly position $\left(29^{\circ} \mathrm{N}\right)$ by April. During this time, the juveniles and subadults migrate separately from the adults. The juveniles and subadults migrate along the coast, whereas the adults occupy the central and deeper areas of the gulf. From May to August, the stock is mostly found in the upper central area of the Gulf of California and is segregated by size. At this time, the adults are found in a band about $16 \mathrm{~km}$ wide along the coast, and the subadults are found beyond the $16 \mathrm{~km}$ limit between 26 and $28^{\circ} \mathrm{N}$. During July, the stock spreads towards the eastern side of the Gulf of California and occupies almost all the central section; there is a greater mixing of sizes at this time. At the end of August and during September, the population begins a migration south towards the entrance of the Gulf of California. A small fraction of the stock, mainly larger individuals (mantle length $>55 \mathrm{~cm}$ ), remains in the upper Gulf of California during winter. Its distribution is confined to the east-central portion of the Gulf of California (Ehrhardt et al. 1983). The migration pattern previously described may be modified during certain conditions, possibly associated with the sea temperature and food availability.

Abundance estimates enable identification of trends in biomass and improve the accuracy of estimates of proportional escapement and the management of the jumbo squid fishery. For these reasons, there is a need to analyze different hypotheses about the biomass of the squid fishery, e.g. by developing models and improving them as new data become available, while taking into account the uncertainty in the variability of the resource (Rodhouse et al. 2006). The use of mark-recapture data may be an alternative method for estimating abundance of jumbo squid, and this statistical procedure could be used when catch-perunit-effort data (e.g. the Leslie-De Lury depletion model [Morales-Bojórquez et al. 2008]) or estimates from research surveys are not available. In the present study, the abundance of jumbo squid in the central Gulf of California was estimated based on mark-recapture data.

\section{MATERIALS AND METHODS}

\section{Field work}

During October 2001 and April 2002, jumbo squid were caught off Santa Rosalía (October) and Guaymas (April) by commercial fishers using hand lines with $30 \mathrm{~cm}$ jigs; the dorsal mantle length of each squid caught was measured to the nearest $\mathrm{cm}$. The sampling periods corresponded to the fishing season, for which spring recruitment (April 2002) and a decline in abundance in autumn (October 2001) have been reported (MoralesBojórquez et al. 2001a, Nevárez-Martínez et al. 2006, 2010, Morales-Bojórquez \& Nevárez-Martínez 2010). Squid were tagged on deck with spaghettitype, plastic cinch-ups (Floy Tag) through the anterior edge of the dorsal mantle; these tags were used in both sampling periods, October 2001 and April 2002. Each individual was marked within approximately $30 \mathrm{~s}$ and was then immediately released. Members of the scientific staff tagged the squid. 
All squid quickly jetted away with no obvious sign of trauma or physical impairment. It is assumed that the survival and recapture rates were not affected by the tagging operation or by the presence of a tag. Squid that showed any visible damage, primarily from cannibalistic attacks by other squid, were not tagged. McAllister et al. (1992) evaluated 9 commercially available tags to determine their suitability for marking rainbow trout Onchorhynchus mykiss and found that the tubing tags (model FT-4 cinch-up, Floy Tag) were the most effective tag for fish maintained in raceways. The spaghetti-type, plastic cinch-up tag also showed high performance when it was used to insert intraperitoneal transmitters into 4 fish species (Butler et al. 2009). The tag we used was selected for its performance because previous trials demonstrated that when the tag was firmly attached to the squid mantle, tag loss was avoided (Markaida et al. 2005). It was assumed that tagged squid could join a different school according to the size class of the school, and predation resulting from small, tagged squid joining schools with larger individuals would not be a factor. Tagged and released squid were not recaptured in the same event. If the tagged squid had remained in its school, the probability of recapture would have been high; this was not observed.

Tag return information was imprinted on the tag, and posters announcing the experiment were distributed at squid-landing ports and at local processing facilities in Santa Rosalía, San Lucas, San Bruno, Mulegé, Loreto and La Paz, Baja California Sur, and in San Carlos and Yavaros, Sonora and Mazatlán, Sinaloa. A monetary reward of \$50 US was offered for each tag returned with information on recapture date and location.

Two tagging events were conducted. During the first event 996 individual jumbo squid were marked in Santa Rosalía (Fig. 1) between 9 and 16 October 2001. In the second event 997 individuals were tagged in Guaymas (Fig. 1) between 3 and 7 April 2002. Recaptures were obtained from the fishing fleet records during 12 to 30 October 2001 and 5 to 30 April 2002. The dorsal mantle length for each squid recaptured was measured to the nearest $\mathrm{cm}$.

Fishery catch data, expressed in kg, were obtained from the Federal Fishing Office in Guaymas and Santa Rosalía. The catch data were converted to numbers per length interval, and a power equation was used to estimate the mantle length-mass relationship. The equation was $M W=\alpha M L^{\beta}$, where $M W$ is the mantle weight $(\mathrm{kg}), \mathrm{ML}$ is mantle length $(\mathrm{cm}), \alpha$ the $y$-axis intercept, and $\beta$ is the slope. The parameters of the power equation were estimated by Nevárez-
Martínez et al. (2006) using data from the 2001-2002 fishing season, where $\alpha=0.82 \times 10^{-5}$ and $\beta=3.15$.

\section{Estimation of the population size}

An estimation of the population size was determined by using the binomial-probability density function. The next maximum-likelihood method was used according to Haddon (2001):

$-\ln L(\mathrm{~N} \mid \eta, \delta, \lambda)=$

$\sum_{i=1}^{\delta} \ln (i)-\left[\sum_{i=1}^{\eta} \ln (i)+\sum_{i=1}^{\delta-\eta} \ln (i)\right]+\eta \ln (\lambda)+(\delta-\eta) \ln (1-\lambda)$

where the objective function is the negative log likelihood $(-\ln L), \delta$ is the number of individuals in the sample size, in this case the total number of squid caught in the central Gulf of California, $\eta$ is the number of marks recaptured, $\lambda$ is the proportion of squid that were marked, determined by $\phi / \mathrm{N}$ where $\phi$ is the number of marked squid ( $\phi=996$ in October 2001 and 997 in April 2002), and $\mathrm{N}$ is the estimated population size, which was computed when Eq. (1) was maximized. The parameter $\mathrm{N}$ was estimated with a nonlinear fit by using the Newton algorithm (Neter et al. 1996). Two estimates of $\mathrm{N}$ were made, the first one for October 2001 and second for April 2002. To estimate the CI $(\alpha<$ 0.05 ) for $\mathrm{N}$ in Eq. (1), the likelihood profile method was used (Venzon \& Moolgavkor 1988, Pawitan 2001). The CI for biomass estimation can be computed using (1) a bootstrap method, which must assume an observation error in mark-recapture data, and (2) an asymptotic method, which commonly yields CIs that are too short in many cases, and important biases are observed with this statistical approach. There are possibilities that the confidence regions can be asymmetric rather than symmetrical ellipses as assumed by asymptotic methods, and if this occurs the likelihood-profile method is preferred because it is computationally more efficient than bootstrapping. (Polacheck et al. 1993, Morales-Bojórquez \& Nevárez-Martínez 2010).

\section{RESULTS}

After the first tagging event in Santa Rosalía (996 ind. tagged between 9 and 16 Oct), 55 individuals were recaptured off Santa Rosalía between 12 and 30 October 2001. This was a tag return rate of $5.5 \%$. In the second tagging event off Guaymas (997 ind. tagged between 3 and 7 April 2002), 17 recaptures were obtained off Guaymas between 5 and 30 April 
2002; this was a tag return rate of $1.7 \%$. The distribution of tagged squid ML ranged from 32.7 to $83 \mathrm{~cm}$, and recaptured squid ranged from 48 to $74 \mathrm{~cm} \mathrm{ML}$. Based on the mark-recapture results, no migration was observed between the coasts of the gulf; this is probably due to the brief durations of these experiments. However, the main advantage of this short time interval is that the natural mortality was assumed to be negligible.

During the study period the individuals that were marked along the west coast of the gulf were recaptured in that region, and those marked along the east coast of the gulf were recaptured there. It was assumed that jumbo squid could migrate during our study period between coasts of the gulf. A range of factors can be attributed to have produced heterogeneity in the population, which would have biased the samples, and, thus, the success of recapture of some individuals was more likely than for others. Such differences in recapture susceptibility among individuals could result from their movement patterns, their behavior, environmental factors, or other reasons (Whitehead 2003). Our study was carried out in the most important biological area for jumbo squid, in the central Gulf of California, because observed growth, recruitment, spawning, feeding, high abundance and the fishing grounds are localized in this area (Boyle \& Rodhouse 2005). In the upper portion (north) and the mouth (south) of Gulf of California, high abundances and captures of jumbo squid have not been reported.

During the first mark-recapture effort (12 to 30 October 2001), a population size of 20.2 million squid was estimated with a CI from 16 to 26.5 million squid ( $p<0.05$, Fig. 2a). The estimated squid biomass was $57000 \mathrm{t}$, which had a CI from 45000 to $74550 \mathrm{t}(\mathrm{p}<0.05)$. During the same time period, the landings along both coasts of the central Gulf of California were $3150 t$, or about 1.1 million squid. For the second mark-recapture effort (5 to 30 April 2002), the population size estimated was 132.6 million squid, with a CI between 85.5 and 222 million squid ( $\mathrm{p}<$ 0.05, Fig. 2b). The biomass estimate was $373100 \mathrm{t}$, which had a CI between $240500 \mathrm{t}$ and $624550 \mathrm{t}$ (p < 0.05). In April the landings on both coasts of the central gulf were $6360 \mathrm{t}$, or about 2.2 million individuals.

\section{DISCUSSION}

Historically, 2 distinct models have dominated analyses of mark-recapture data for open animal populations; the Jolly-Seber (JS) model (Jolly 1965, Seber
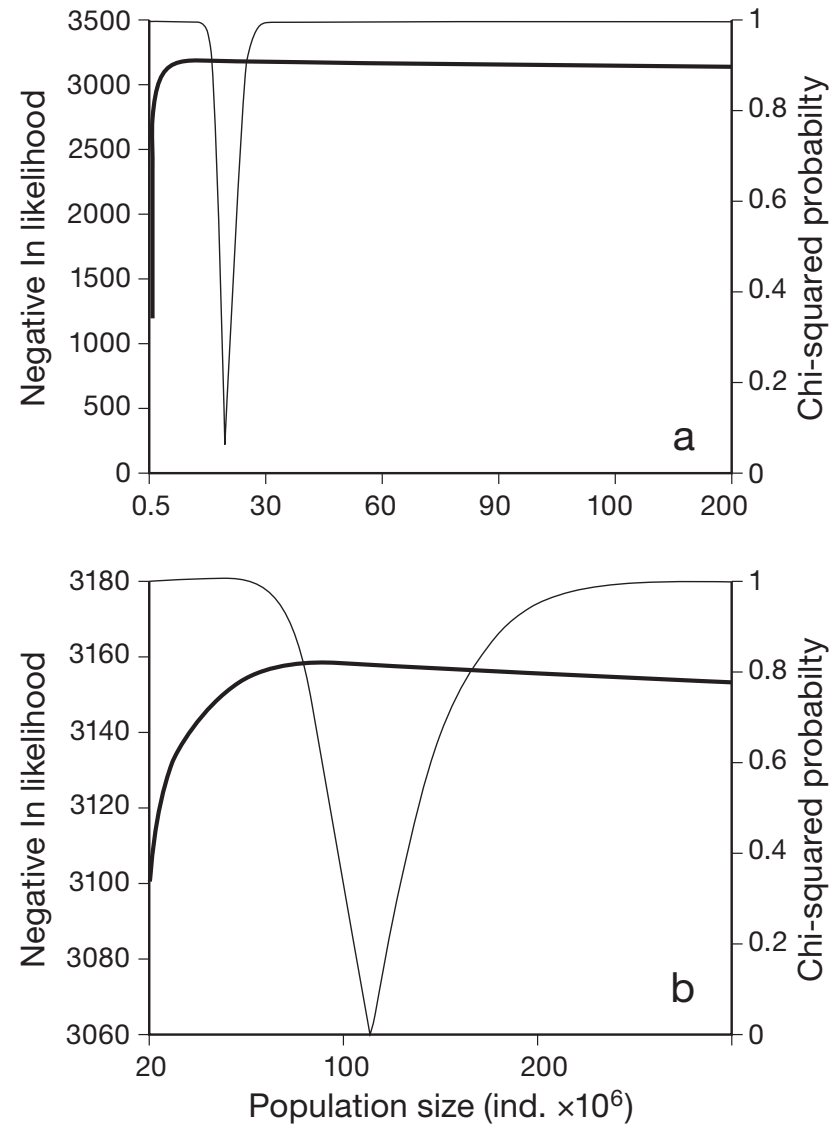

Fig. 2. Dosidicus gigas. Number of individuals estimated during (a) October 2001 and (b) April 2008. Thick line: likelihood profile of population size for binomial distribution; thin line: CI defined Chi-squared distribution

1965), which is used to estimate abundance, and the Cormack-Jolly-Seber (CJS) model, which is used in survival probabilities only (Cormack 1964). In the JS and CJS models, data are obtained from the recapture of marked animals at subsequent marking or recapture occasions. These activities may be either the live recapture of animals during trapping operations or live resightings over a short time period during which the population is assumed closed. An important assumption of the JS model is that if animals leave the study population, they do so permanently.

The information may be provided by marked individuals in 3 ways: (1) live recapture of animals during marking operations; (2) recovery of marks from animals found dead between marking occasions; (3) reported sightings (alive) of marked animals between marking occasions. Most studies are designed so that just one type of data provides the primary information for the construction of a mark-recapture model. However, these multiple sources of information on marked animals can be exploited in the analysis 
phase of the study to increase precision of key parameter estimates (White \& Burnham 1999).

In the central Gulf of California the jumbo squid population is concentrated and movements occur between both coasts (Markaida et al. 2005). However, during the study period, the mark-recapture data did not show evidence of individuals caught off opposite coasts. The artisanal fleets do not cross the gulf, and the vessel fleet from Guaymas expends $90 \%$ of its fishing effort in its own fishing ground. The movements of squid have been reported from 1996 (HernándezHerrera et al. 1998) and migrations are not extensive in the gulf. However, during certain conditions, possibly associated with sea surface temperature, principally during El Niño events, the distribution of the squid population can be modified as individuals move out of the gulf (Morales-Bojórquez et al. 2001a). During years when the California Current is warmer, the distribution of squid definitively changes in the Gulf of California, and the pattern of movement is modified. During our study period 2001 and 2002, warmer or cooler than normal conditions were not reported in the Gulf of California. Consequently, an extensive migration was not observed, and the individuals remained in the central Gulf area. This zone is the most representative zone of distribution of Dosidicus gigas (Fig 1). Different biological events in this region related to the population dynamics and demography of $D$. gigas have been identified. Staaf et al. (2008) found an egg mass at a depth of $16 \mathrm{~m}$, which was the first evidence of jumbo squid spawning in this area. Rosas-Luis et al. (2008) analyzed an ecosystem model for the central Gulf of California, which showed that $D$. gigas has an important role in the overall energy flow. It is the main food item for most top predators and an important predator of organisms at lower trophic levels. Davis et al. (2007) reported on the activity and trophic interactions between the sperm whale Physeter macrocephalus and the jumbo squid.

In the central Gulf of California jumbo squid are widely distributed, and vertical and horizontal movements have been observed (Markaida et al. 2005, Gilly et al. 2006). The most important biological features, such as reproduction and spawning (Markaida 2006), growth (Hernández-Herrera et al. 1998, Nevárez-Martínez et al. 2006, 2010), migration (Markaida et al. 2005) and recruitment (Morales-Bojórquez et al. 2001c), have been described in the area. Consequently, the fishing activity is well known in this region (Morales-Bojórquez et al. 2001a, MoralesBojórquez \& Nevárez-Martínez 2010).

Gilly et al. (2006) and Bazzino et al. (2010) explained that a migration of jumbo squid from the fish- ing ground off Santa Rosalía to those off Guaymas occurred at an average estimated velocity of $8 \mathrm{~km}$ $\mathrm{d}^{-1}$, followed by a reciprocal migration back to Santa Rosalía in May. This trans-gulf migration was previously reported by Morales-Bojórquez et al. (2001a). These squid moved over a straight-line distance of almost $200 \mathrm{~km}$ in $7 \mathrm{~d}$, or $100 \mathrm{~km}$ in 3 to $4 \mathrm{~d}$, which is consistent with an average migration rate of about $30 \mathrm{~km} \mathrm{~d}^{-1}$ (Gilly et al. 2006). The temporary nature of this experiment with mark-recapture was based on the behavior of the squid in the water column; it allowed each marked individual to mix with the rest of the population. The marked squid jetted strongly downwards immediately after release, and during the next $7 \mathrm{~d}$ the squid could have crossed the gulf.

However, a straight-line movement is not realistic for the whole population. According to Burnham (1993) there are differences between permanent and random movements. Permanent movement is often listed as an assumption for the CJS model; however, Burnham (1993) has shown that in the CJS model permanent movement is indistinguishable from random movement. Under random movement, a squid may leave the population segment where it is at risk of capture and later return. However, the probability that the squid is at risk of capture on a particular marking occasion does not depend on whether it was at risk of capture on earlier marking occasions. Under random movement, the CJS survival parameter represents a true survival rate and the capture probability and movement probabilities are confounded (Burnham 1993). We assumed that Dosidicus gigas could show a random movement in the central Gulf of California, as this condition would allow the marked squid to mix with the population.

The jumbo squid migrates across the Gulf of California on a seasonal basis. The movement from Santa Rosalía to Guaymas has been observed during November and early December (Markaida et al. 2005). In late May and early June the reverse movement was reported and could be influenced by the reproductive pattern of the species; Markaida \& Sosa-Nishisaki (2001) explained that maturing females obtain their reproductive investment from feeding. Thus, the alternate upwelling system of the central Gulf of California could supply food all year round to allow the squid to mature. It is assumed that the seasonal variability in biomass is related to the population dynamics of the squid in the gulf. During October 2001 population abundance was expected to be low, in comparison with April, which is when recruitment is observed in the central gulf. NevárezMartínez et al. $(2006,2010)$ analyzed the spatial and 
temporal variability in recruitment from 2002 to 2008. Warmer waters caused by El Niño conditions in the California Current are coincident with low recruitment. Cooler waters that are identified with negative anomalies in the sea surface temperature caused by La Niña were related to high recruitment. Previously, Hernández-Herrera et al. (1998) and NevárezMartínez et al. (2000) identified the recruitment event during early spring in the central Gulf of California.

According to Markaida et al. (2005) and Gilly et al. (2006), the movements of jumbo squid into the Gulf of California showed the movement described by Ehrhardt et al. (1983). However, this movement was not random; during the 1982-1983 El Niño event identified in the California Current, the abundance and distribution of jumbo squid were modified by squid moving out of the gulf. A similar movement of the squid population was documented during the 19971998 El Niño event (Morales-Bojórquez et al. 2001a).

An important feature of mark-recapture studies is that a researcher can only capture squid associated with the trapping site where they were marked. Furthermore, there is usually little control over exactly which squid are at risk of capture, and squid available for capture in one trapping session may not be available for trapping in other sessions. The JollySeber model assumes that squid movement is permanent (Seber 1982), meaning that if a squid leaves the component of the population that is at risk of capture, then it is not permitted to return. In many studies, such an assumption may be hard to justify, and movement of squid both in and out of the Gulf of California may occur. Therefore, it is important that analyses be flexible enough to allow other types of squid movement. Random movement (Burnham 1993) occurs if the risk of capture at time $i$ for squid in the population at $i-1$ is the same for all squid. However, it is just one possible type of movement in and out of the Gulf of California by squid. A more general model considered by Kendall et al. (1995) in the context of Pollock's (1982) robust design is Markov movement, in which the probability a squid is at risk of capture at time $i$ depends on whether it was at risk of capture at time $i-1$. Permanent movement is a special case of Markov movement where the probability of subsequent capture is 0 for individuals not at risk of capture at $i$. Generalizations of the Markov movement model also can be envisaged that allow dependence to extend for more than one time period, for example, the memory model of Brownie et al. (1978).

In the Gulf of California, the abundance of jumbo squid has been estimated from catch-per-unit-effort (CPUE) data, survey research data and catch-at-age or catch-at-size analysis (Hilborn \& Walters 1992). Estimates of annual recruitment are updated as the fishing season progresses by using current estimates of abundance obtained by the monitoring of catch and escapement or by fishery-independent data (Hernández-Herrera et al. 1998, Nevárez-Martínez et al. 2000).

Despite having different estimation methods over time, the present study does not compare abundance estimates. We show that mark-recapture data could be an additional option to the known methods for assessing populations of jumbo squid. If the comparison is desirable, then we must use a criterion that considers the number of parameters in the candidate models; with an increasing number of parameters, the squared bias of the estimates of the individual parameters goes down, but parameter uncertainty (or variance) is greater. By treating the problem as one of simply balancing variance and bias, one approach is to make use of Akaike's information criterion (AIC) (Burnham \& Anderson 2002). If AIC is used, one should select the model that yields the smallest value of AIC among the models in the candidate model set, not simply because it provides some balance between precision and fit, but because this model is estimated to be the closest to the unknown reality that generated the sample data from among the candidate approximating models being considered (Burnham \& Anderson 2002).

In this study, we did not make comparisons among candidate models (CPUE, survey research data and catch-at-age or catch-at-size analysis). These models have different statistical criteria in algorithms (sum of squares or likelihood function), and the comparison is not possible. Instead, in the future we could compare different sample designs for analysis of mark-recapture data, depending on the re-encounter mechanisms operating. Possible survival and reencounter events after release at time $i$ and up until time $i+1$ may be analyzed as follows: (1) the squid may die with no encounter (alive or dead) after release; (2) the squid may die without being resighted before death, but be found after death; (3) the squid may be resighted alive, then die and be found after death; (4) the squid may survive the interval without being resighted and avoid capture at $i+1$; (5) the squid may survive the interval without being resighted and be caught at $i+1$; (6) the squid may survive the interval and be resighted alive during the interval but avoid capture at $i+1 ;(7)$ the squid may survive the interval, be resighted alive during the interval and be resighted again and caught at $i+1$ (White \& Burnham 1999). 
The use of several stock assessment methods is necessary because we must analyze alternative biomass models, and take into account the uncertainty in abundance variability. The mark-recapture approach may be an alternative to other methods for abundance estimation. The results showed the variability in biomass of jumbo squid in the Gulf of California, and the mark-recapture experiments identified 2 different periods in abundance: during October when the biomass declines, and in April when the squid population increases at the time when the recruitment occurs. The mark-recapture method may be applied if the jumbo squid population is concentrated in the central Gulf of California; however, if the population has extensive migrations associated with El Niño events, as have been observed in the past (1982-1983 and 1997-1998), the method should not be considered.

Acknowledgements. We thank Instituto Nacional de Pesca, Centro Regional de Investigación Pesquera Guaymas, for support in obtaining statistical data of jumbo squid. A.H.H. thanks Comisión de Operación y Fomento de Actividades Académicas del Instituto Politécnico Nacional, and Programa de Estímulos al Desempeño de los Investigadores del Instituto Politécnico Nacional.

\section{LITERATURE CITED}

Bazzino G, Gilly WF, Markaida U, Salinas-Zavala C, RamosCastillejos J (2010) Horizontal movements, vertical-habitat utilization and diet of the jumbo squid (Dosidicus gigas) in the Pacific Ocean off Baja California Sur. Prog Oceanogr 86:59-71

Beddington JR, Rosenberg AA, Crombie JA, Kirkwood GP (1990) Stock assessment and the provision of management advice for the short fin squid fishery in Falkland Islands waters. Fish Res 8:351-365

Boyle P, Rodhouse P (2005) Cephalopods. Ecology and fisheries. Blackwell Science, Oxford

Brownie C, Anderson DR, Burnham KP, Robson DS (1978) Statistical inference from band recovery data - a handbook. US Fish Wildl Serv Resour Publ 131. US Fish Wildl Serv, Washington, DC

Burnham KP (1993) A theory for combined analysis of ring recovery and recapture data. In: Lebreton JD, North P (eds) Marked individuals in bird population studies. Birkhauser Verlag, Basel

Burnham KP, Anderson DR (2002) Model selection and multi-model inference: a practical information-theoretic approach. Springer, New York, NY

Butler GL, MacKay B, Rowland SJ, Pease BC (2009) Retention of intraperitoneal transmitters and post-operative recovery of four Australian native fish species. Mar Freshw Res 60:361-370

Cormack RM (1964) Estimates of survival from the sighting of marked animals. Biometrika 51:429-438

> Davis RW, Jaquet N, Gendron D, Markaida U, Bazzino G, Gilly W (2007) Diving behavior of sperm whale of a major prey species, the jumbo squid, in the Gulf of California, Mexico. Mar Ecol Prog Ser 333:291-302

Ehrhardt NM, Jacquemin PS, García F, González G, López JM, Ortíz J, Solis A (1983) On the fishery and biology of the giant squid Dosidicus gigas in the Gulf of California, Mexico. In: Caddy JF (ed) Advances in assessment of world cephalopod resources. FAO Fish Tech Pap 231. UN FAO, Rome

Gilly WF, Markaida U, Baxter C, Block B and others (2006) Vertical and horizontal migrations by the jumbo squid Dosidicus gigas revealed by electronic tagging. Mar Ecol Prog Ser 324:1-17

Haddon M (2001) Modeling and quantitative methods in fisheries. Chapman and Hall/CRC Press, Boca Raton, FL

Hernández-Herrera A, Morales-Bojórquez E, CisnerosMata MA, Nevárez-Martínez MO, Rivera-Parra GI (1998) Management strategy for the giant squid (Dosidicus gigas) fishery in the Gulf of California, Mexico. Calif Coop Oceanic Fish Invest Rep 39:212-218

Hilborn R, Walters C (1992) Quantitative fisheries stock assessment. Choice, dynamics and uncertainty. Chapman \& Hall, New York, NY

> Jolly GM (1965) Explicit estimates from capture-recapture data with both death and immigration-stochastic model. Biometrika 52:225-247

Kendall WL, Nichols JD, Hines JE (1995) Estimating temporary emigration using capture-recapture with Pollock's robust design. Ecology 78:563-578

McAllister KW, McAllister PE, Simon RC, Werner JK (1992) Performance of nine external tags on hatchery-reared rainbow trout. Trans Am Fish Soc 121:192-198

> Markaida U (2006) Population structure and reproductive biology of jumbo squid Dosidicus gigas from the Gulf of California after the 1997-1998 El Niño event. Fish Res 79:28-37

Markaida U, Sosa-Nishisaki O (2001) Reproductive biology of jumbo squid Dosidicus gigas in the Gulf of California, 1995-1997. Fish Res 54:63-82

Markaida U, Rosenthal JJ, Gilly W (2005) Tagging studies on the jumbo squid (Dosidicus gigas) in the Gulf of California, Mexico. Fish Bull 103:219-226

> Morales-Bojórquez E, Nevárez-Martínez MO (2010) Catchat-size analysis for Dosidicus gigas in the central Gulf of California, Mexico. Fish Res 106:214-221

> Morales-Bojórquez E, Cisneros-Mata MA, Nevárez-Martínez MO, Hernández-Herrera A (2001a) Review of stock assessment and fishery research for Dosidicus gigas in the Gulf of California, Mexico. Fish Res 54:83-94

Morales-Bojórquez E, Hernández-Herrera A, Nevárez-Martínez MO, Cisneros-Mata MA, Guerrero-Escobedo F (2001b) Population size and exploitation of giant squid (Dosidicus gigas D'Orbigny, 1835) in the Gulf of California, Mexico. Sci Mar 65:75-80

Morales-Bojórquez E, Martínez-Aguilar S, ArreguínSánchez F, Nevárez-Martínez MO (2001c) Estimations of catchability-at-length for the jumbo squid (Dosidicus gigas) in the Gulf of California, Mexico. Calif Coop Oceanic Fish Invest Rep 42:167-171

Morales-Bojórquez E, Hernández-Herrera A, Cisneros-Mata MA, Nevárez-Martínez MO (2008) Improving estimates of recruitment and catchability of jumbo squid Dosidicus gigas in the Gulf of California, Mexico. J Shellfish Res 27: 1233-1237

Neter J, Kutner MH, Nachtschien J, Wasserman W (1996) Applied linear statistical models. McGraw-Hill/Irwin 
Series in Statistics, Boston, MA

Nevárez-Martínez MO, Hernández-Herrera A, MoralesBojórquez E, Balmori-Ramírez A, Cisneros-Mata MA, Morales-Azpeitia R (2000) Biomass and distribution of the jumbo squid (Dosidicus gigas D'Orbigny, 1835) in the Gulf of California, Mexico. Fish Res 49:129-140

- Nevárez-Martínez MO, Méndez-Tenorio F, Cervantes C, López-Martínez J, Anguiano-Carrasco M (2006) Growth, mortality, recruitment, and yield of the jumbo squid (Dosidicus gigas) off Guaymas, México. Fish Res 79:38-47

Nevárez-Martínez MO, Morales-Bojórquez E, CervantesValle C, Santos JP, López-Martínez J (2010) Population dynamics of the jumbo squid (Dosidicus gigas) fishery off Guaymas, Mexico. Fish Res 106:132-140

Pawitan Y (2001) In all likelihood: statistical modeling and inference using likelihood. Oxford Science Publications, Oxford

Polacheck T, Hilborn R, Punt A (1993) Fitting surplus production models: comparing methods and measuring uncertainty. Can J Fish Aquat Sci 50:2597-2607

Pollock KH (1982) A capture-recapture design robust to unequal probability of capture. J Wildl Manag 46:757-760

Rodhouse P, Waluda C, Morales-Bojórquez E, HernándezHerrera A (2006) Fishery biology of the Humboldt squid,

Editorial responsibility: Hans Heinrich Janssen,

Oldendorf/Luhe, Germany
Dosidicus gigas, in the Eastern Pacific Ocean. Fish Res 79:13-15

Rosas-Luis R, Salinas-Zavala CA, Koch V, del Monte-Luna P, Morales-Zárate MV (2008) Importance of jumbo squid Dosidicus gigas (D'Orbigny, 1835) in the pelagic ecosystem of the central Gulf of California. Ecol Model 218: 149-161

Seber GAF (1965) A note on the multiple-recapture census. Biometrika 52:249-259

Seber GAF (1982) The estimation of animal abundance and related parameters. Griffin, London

> Staaf D, Camarillo-Coop S, Haddock SH, Nyack A and others (2008) Natural egg mass deposition by the Humboldt squid (Dosidicus gigas) in the Gulf of California and characteristics of hatchlings and paralarvae. J Mar Biol Assoc UK 88:759-770

> Venzon DJ, Moolgavkor SH (1988) A method for computing profile-likelihood-based confidence intervals. Appl Stat 37:87-94

> White GC, Burnham KP (1999) Program MARK: survival estimation from population of marked animals. Bird Study 46:S120-S139

Whitehead H (2003) Sperm whales: social evolution in the ocean. University of Chicago Press, Chicago, IL

Submitted: April 30, 2011; Accepted: December 20, 2011

Proofs received from author(s): March 4, 2012 